\title{
情報技術と計測技術の融合による視覚的質感の高速計測*
}

渡辺 義浩 ${ }^{1}$

\section{High-speed Acquisition of Reflective Properties Based on the Fusion of Information and Measurement Technologies}

Yoshihiro WatANABE

1.はじめに

我々の視覚で捉えられる像は，大きく分けて物体の 3 次元形状, 照明, 反射特性から構成される. 具体的には, 物体の表面にあたった照明が，物体表面の形状と反射特 性に応じて, 反射光を生成し, 網膜に像を結ぶ。結果と して捉えられるFig.1のような見えを通して，ぴかぴ かしている，ざらざらしているなどといった視覚的質感 が得られる。このような視覚的質感には反射特性が大き く関係している1).

反射特性とは，物体を介したときの入射光輝度に対す る観測光輝度の比率を指す。この特性は, 光の入射方向 と観測方向によって変動する。このように，反射特性は 多次元であるため，計測には時間を要する.

しかし，高速な視覚的質感の計測が実現できれば，広 い応用分野に扔いて役立つ可能性が高い，例えば，博物 館・美術館・図書館に所蔵されている膨大な数の工芸 品・美術品・書籍のデジタルアーカイブ, 大量生産を伴 う産業・農業分野での生産・検查, 映像制作分野での編 集作業に扔いて, 反射特性の取得は重要な役割を果たす ことが期待できる．しかし，計測時間がネックとなり， 多くの場合は利用が困難であった。

このような背景の下, 本稿では高速な視覚的質感の計 測に向けて, 反射特性計測の回数を最小化しつつも, 高 い質感再現を目指した手法を紹介する，糸口は，反射特 性の膨大なデー夕構造に扔けるスパース性にある。この アプローチのもと, 計測技術と情報技術の両面からの融 合によって新たに構築した手法となっている.

\section{2. 反射特性}

\section{1 定義}

ある表面上の 1 点の反射特性は，双方向反射率分布関 数 (BRDF: Bi-directional Reflectance Distribution Function）によって表現される2),3).

\footnotetext{
* 原稿受付 2020 年 7 月 20 日

東京工業大学

（） 226-8502 神奈川県横浜市緑区長津田町 4259-G2-31,

E-mail : watanabe.y.cl@m.titech.ac.jp)
}

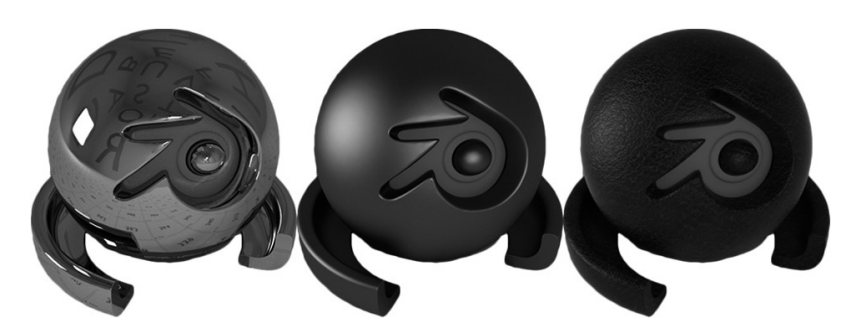

Fig. 1 Our perceived images and 'Shitsukan'.

$$
f_{r}(\boldsymbol{L}, \boldsymbol{V})=\frac{d L_{r}(\boldsymbol{V})}{d E_{i}(\boldsymbol{L})}
$$

ここで, $\boldsymbol{L}$ は照明の入射方向, $\boldsymbol{V}$ は観測方向を表す. $d L_{r}$ は放射輝度, $d E_{i}$ は放射照度を表す，特性として BRDF は非負である。またへルムホルッの相反性より 入射方向と観測方向を入れ替えても值は変化しない. す なわち, $f_{r}(\boldsymbol{L}, \boldsymbol{V})=f_{r}(\boldsymbol{V}, \boldsymbol{L})$ を満たす。ささらに，エネル ギー保存則より反射光のエネルギー総和は入射エネル ギーを超えない。すなわち，下式を満たす。

$$
\forall \boldsymbol{L}, \int_{\Omega_{+}} f_{r}(\boldsymbol{L}, \boldsymbol{V})(\boldsymbol{N} \cdot \boldsymbol{L}) d \boldsymbol{V} \leq 1
$$

ここで, $\boldsymbol{N}$ は注目する点の法線方向を表す．また， $\Omega_{+}$ は観測できる表面の上半球である.

また, 入射方向と観測方向を固定し, 法線を軸に物体 を回転させたとき, 観測光が変化する反射特性を異方性, 変化しない反射特性を等方性と呼ぶ. 異方性はサテンな どの布地, ヘアライン加工された車のボデイなどが持つ 特殊な特性である.

\section{2 モデル}

コンピュータグラフィクスの分野では BRDF をパラ メトリックな数式モデルで表現することが主流である.

このとき, BRDF は拡散反射成分と鏡面反射成分の和 で表現される. 拡散反射とは, 全ての方向に一様な放射 輝度で反射される成分である. 鏡面反射は, 鏡のように 反射する成分であり, 入射方向と観測方向に依存する成 分である，例えば，鏡面反射のモデルとして下式がある.

$$
f_{r}^{\text {spec }}(\boldsymbol{L}, \boldsymbol{V})=\frac{D F G}{\boldsymbol{N} \cdot \boldsymbol{V}}
$$

ここで $D$ は微小面の法線方向の分布を表す微小面分布 関数項, $F$ はフレネル反射項, $G$ は微小面の凹凸により 
生じる自己遮蔽などを表す幾何減衰項である，各項は法 線方向 $\boldsymbol{N}$, 入射方向 $\boldsymbol{L}$, 観測方向 $\boldsymbol{V}$ を引数とする非線 形関数で表される。コンピュータグラフィックスにおい て使用される場合は問題ないが, 計測のような逆問題で は，モデルの非線形性が高いため，精度よくモデルパラ メー夕を求めることは困難である。また，このような数 式モデルは実世界の特性を近似したものであり，観測さ れるデータと完全には合わない。この点も計測における 逆問題を解く上で安定した高精度化を困難にしている.

これに対して，BRDF を密に入射方向，観測方向ご とに密にサンプリングし, 大規模なデータセットとして 表現する方法がある ${ }^{4), 5)}$. BRDF は入射・観測方向に対 して，4 次元の自由度を持っているが，等方性を仮定す ることで 3 次元にまで削減が可能である。例えば， 1 度 ごとに特性を保持した場合，その要素数は $90 \times 90 \times$ $180=1,458,000$ となる。このすべてのデー夕を計測に よってまともに得ることは困難であるため，いかにして 効率化するかが課題となる.

\section{3 視覚的質感}

前節で述べたように，視覚的質感のもととなる網膜像 は, 照明, 3 次元形状, 反射特性の 3 つから生成される. 実世界上では順過程としてこの 3 つが相互作用するが, 人間は網膜像から逆過程としてこの 3 つを推定する必要 がある。しかし，上記 3 つの要素に対して，同じ網膜像 を生成する複数の可能性がありうるため，この逆問題を 一意に解くことは理論的には不可能である。では，人間 はどのように視覚的質感を得ているのか？この問いに対 して，様々な視覚科学の研究が報告されている11.

例えば, 反射に関わる光沢感や材質の知覚的な弁別能 力を調査したものがある $\left.{ }^{6)}, 7\right), 8$. 反射特性の取りうる範 囲は広い．また，拡散反射成分よりも鏡面反射成分の方 がはるかに大きい。しかし，人間は限られた視覚機能の もとで，広範囲にわたる特性のわずかな違いも正確に捉 えることができる，このことから，反射特性の数值的な 差が, 線形的に人間の知覚的な差に一致しているわけで はないと考えられる。計測された反射特性を，人間に提 示する応用で最終的には利用すると想定した場合，その 計測精度はこのような知覚的特性を考慮に入れる必要が あることが分かる.

\section{3. 反射特性の計測}

対象表面の 1 点にのみ注目し，同点の反射特性を計測 するものを点サンプリングベースの計測と呼ぶ. 本稿で は, 特に等方性の反射特性について, 同タイプの計測の 高速化に着目する。 また，コンピュータグラフィクスで 用いられるような数式モデルではなく, 実際の BRDF データセットから直接的にモデル化する表現に着目する。

例えば，計測回数を削減する試みとして，ウェーブ レット変換を用いた表現のもとで正反射方向付近以外の サンプリング密度を下げることで 69,000 回まで抑えた
手法 ${ }^{9)}$ ，データセットの線形結合で未知の BRDF を表現 することで 800 回まで抑えた手法がある ${ }^{9)}$ 。また，主成 分分析によって次元圧縮した表現のもと，同主成分係数 を求める際の行列の条件数が最小になるように，サンプ リング方向を選ぶことで, 20 回程度にまで抑えた手法 がある10)

しかし，計測精度にはまだ向上の余地がある。また， サンプリング条件は手法の精度を上げるように最適化さ れる必要があり，自由に選ぶことが難しい．このため, 計測装置をコンパクトに設計することが困難であった。

\section{2. 機械学習を用いた高精度・少数サンプリングを 両立する反射特性の計測}

\section{1 概要}

本手法では, BRDF の表現が復元問題を解く上でも 適した性質を備えるように，手法全体を設計する枠組み に着目する ${ }^{12)}$. 特に, 従来手法では，モデルの生成とモ デルパラメータの推定のフェーズが分離しており, 性能 向上の余地がある点に着目する。

そこで，ニューラルネットワークを用いて，サンプリ ングデータを入力とし，未観測の BRDF をダイレクト に出力する推定器を提案する。このように推定器を設計 することにより，モデルの生成とモデルパラメータの推 定が同時に最適化されるため, 性能の向上が期待される. また，本手法ではあらかじめ定められたサンプリング方 向のデータに対して, 推定器が最適化される.このため, $\mathrm{BRDF}$ モデル由来の得意不得意なサンプリング方向が 存在しないことが期待される，従って，反射特性の性質 を表現するのに経験的に適した方向が含まれていれば, 様々なサンプリングセットに対して自在に推定器を構築 可能である，本手法を用いることで，既存の計測装置を 転用したり，よりコンパクトな新しい計測装置を実現し たりすることができると考えられる。

\section{2 手法}

本手法では，より効率的に等方性の BRDF を表現す るためにハーフベクトル座標系 ${ }^{11)}$ を用いる。この場合， サンプリング方向 $(\boldsymbol{L}, \boldsymbol{V})$ は, $\boldsymbol{\omega}=\left(\theta_{h}, \theta_{d}, \phi_{d}\right)$ の 3 自由度 で表現される。この座標系のもとで各角度を 1 度刻みで 取った場合，1つのマテリアルに対する BRDF の次元 数は前述と同様に $1,458,000$ 次元となる. この次元数は, 学習のために用意できるマテリアルの数よりも多い。こ の点はニューラルネットワークの学習に置いて問題とな る.そこで, 本手法では, 従来の数式モデルと同様に, サンプリング方向 $\omega$ に対して $\operatorname{BRDF}$ 值 $\rho \in \mathbb{R}^{1}$ を出力す る関数を導入する.

$$
\rho=f_{r}(\boldsymbol{\omega} ; \boldsymbol{\alpha})
$$

ここで, $\boldsymbol{\alpha} \in \mathbb{R}^{k}$ は各マテリアルに対して定まるパラ メータである。これに対して，少数のサンプリングデー 夕 $\tilde{\boldsymbol{\rho}} \in \mathbb{R}^{n}$ からマテリアルパラメータ $\boldsymbol{\alpha}$ を求める関数 $g$ が存在すると仮定する. 


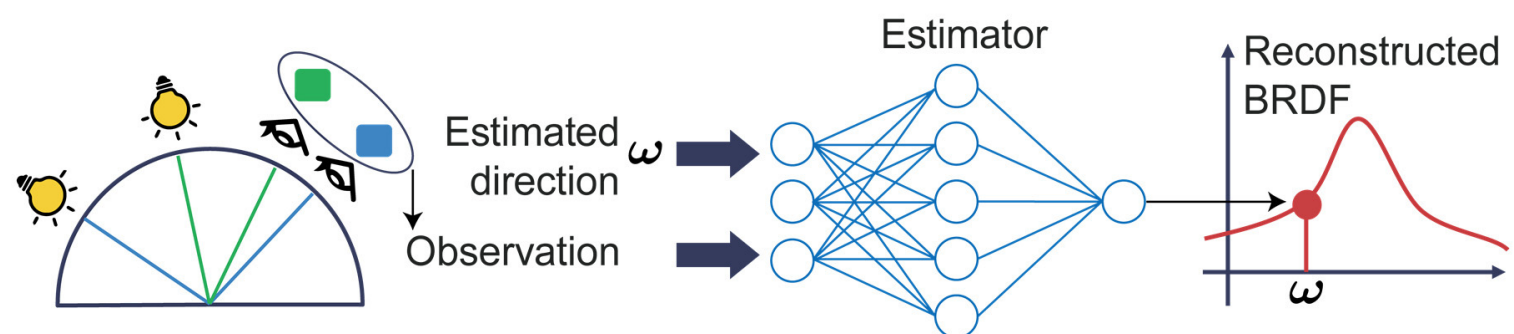

Fig. 2 Proposed workflow for the BRDF measurement.

$$
\boldsymbol{\alpha}=g(\tilde{\boldsymbol{\rho}})
$$

従来は BRDF モデル $f_{r}$ が予め与えられた状態で，マ テリアルパラメータを推定する問題 $g$ を解いていた。 $g$ の形は $f_{r}$ から決定されるため, 問題を解く精度を上げ るためにサンプリングセット $\tilde{\boldsymbol{o}}$ をチューニングするア プローチが採られていたと考えることができる。これに 対して, 本手法では $f, g$ の合成として推定器を表す関 数 $\tilde{f}_{r}$ を考える.

$$
\widetilde{f}_{r}(\boldsymbol{\omega}, \widetilde{\boldsymbol{y}})=f_{r}(\boldsymbol{\omega}, g(\widetilde{\boldsymbol{y}}))
$$

この関数 $\widetilde{f}_{r}$ を反射特性推定器と呼ぶ。この推定器 $\widetilde{f}_{r}$ をニューラルネットワークを用いて学習する。この 推定器の学習では, 与えられたサンプリング方向から BRDF を推定する問題と, それに応じた BRDF モデル が同時に最適化される. Fig. 2 に学習された推定器を用 いた計測と復元の手順を示す.

次に精度向上のためのテクニックについて述べる．本 手法では, サンプリング方向を $\boldsymbol{\omega}=\left(\sin \theta_{h}, \cos \theta_{d}, \cos 2 \phi_{d}\right)$ に変換してニューラルネット ワークに入力する. 3 番目の要素の $\phi_{d} \rightarrow \cos 2 \phi_{d}$ は, 2.1 節で述べたへルムホルツの相反性を満たすための変 換である. ハーフベクトル座標系では BRDF が $\phi_{d}$ に関 して周期 $\pi$ であると言い換えられる。しかし，単純に $\phi_{d} \in[0, \pi]$ で学習を行うと, $\phi_{d}=\pi$ での BRDF の連続 性が保証されない。そこで，等方性の条件から仮定可能 な下式の鏡像対称性に着目する。

$$
f_{r}\left(\phi_{d}=\phi\right)=f_{r}\left(\phi_{d}=-\phi\right)=f_{r}\left(\phi_{d}=\pi-\phi\right)
$$

このとき, $\phi_{d}=\pi / 2$ で対称となる.よって, $\phi_{d}$ は $\cos 2 \phi_{d}$ で置換可能であり, この変換により $\phi_{d}=\pi$ での 連続性は保証される。 また, $\left(\theta_{h}, \theta_{d}\right) \rightarrow\left(\sin \theta_{h}, \cos \theta_{d}\right)$ は $\theta_{h}=0$ 付近の正反射および $\theta_{d}=\pi / 2$ 付近のフレネル反 射を「より詳しく見る」ように学習させる変換である. このように, データセットを単純に学習させるのではな く, 物理的な拘束条件を明示的に満たして, 精度を向上 するような工夫が施されている.

さらに学習時の損失関数には, 下式を出力された BRDF 值に作用させたものの 2 乗誤差を用いた。

$$
\begin{gathered}
\rho \rightarrow \log \left(\rho \cos _{\mathrm{W}}+\epsilon\right) \\
\cos _{\mathrm{W}}=\max \{(\boldsymbol{N} \cdot \boldsymbol{L})(\boldsymbol{N} \cdot \boldsymbol{V}), \epsilon\}
\end{gathered}
$$

これは BRDF 值の差を人間の知覚に近くなるように変 換したものである. $\epsilon$ は定数である. 2.3 節で述べたよ うにBRDF 值そのものの差は, 人間の質感と合わない.
視覚的な質感としての計測精度を高めるためにこのよう な工夫が必要となる.

ニューラルネットワークの学習には等方性の BRDF を集めた MERL データベース ${ }^{5)}$ 用いた。同データ ベースの 90 マテリアルを学習に使用し，10 マテリアル は評価のみに使用した。また，全結合の多層ニューラル ネットワークのアーキテクチャで学習を行う．活性化関 数にはSwish を用いた。

\section{2 結果}

Fig. 3 にシミュレーションによる推定結果を示す。こ の実験では 3 つのサンプリング方向のみから推定してい る. 図は球に対して前方と後方から 2 つのス゚ット光を 照射した場合の仮想像を BRDF に基づいて生成してい る. 図の左側が推定結果，右側が真值である。上段が フェノール樹脂，下段が銀である。これらのマテリアル は前節で述べた通り，MERL データベースの学習に使 用しなかったものである. 3 方向のみであるにもかかわ らず，残りの $1,457,997$ 次元の BRDF 值が高い精度で 復元されていることが分かる.

次に実機による結果について述べる，従来はロボット アームを備えたゴニオリフレクトメータや，多数の光源 を配置した半球のドーム状のシステムなど特殊で大型の 装置を用いる必要があった。一方，本手法では，サンプ リング方向を選ぶ自由度がユーザ側に提供されている。 このため，ユーザが計測装置の設計上で要請される条件 にも柔軟に対応できる可能性が高い，本稿では，手軽か つ高速な反射特性計測を工業的に広く使用できる将来性 に着目し，光沢計の転用を図る，光沢計は，品質管理の ために既に工業分野で広く使われているが，光沢度と呼
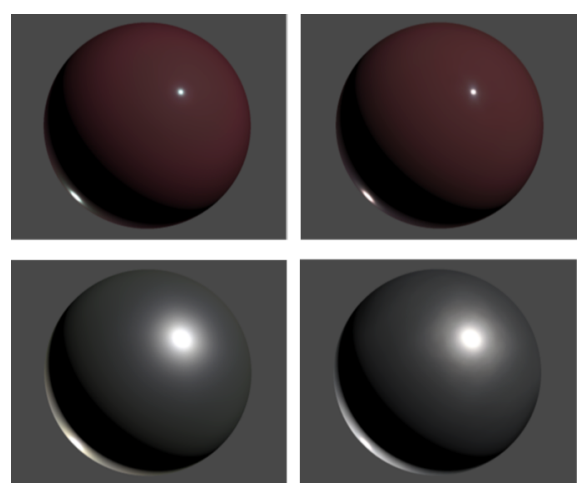

Fig. 3 Simulation results. 


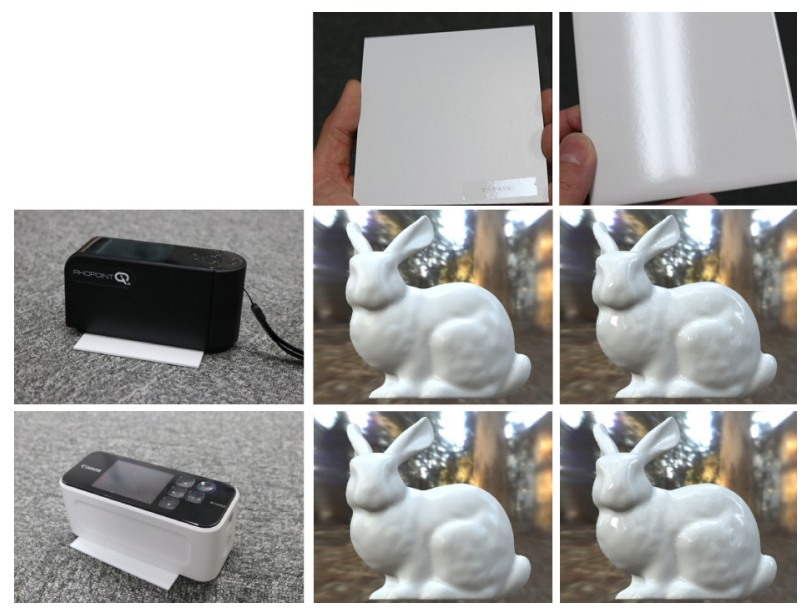

Fig. 4 Results using glossmeters.

ばれる值を計測する目的でのみ利用されていた。 反射特 性全体を復元できるデバイスとして転用できれば，その インパクトは大きい.

Fig. 4 に 2 種類の光沢計を用いて計測した結果を示す. 本実験では, 計測された複数のサンプリング方向におけ る光沢度を BRDF 值に変換し, ニューラルネットワー クに入力した. 図の左には 2 種類の光沢計を用いて計測 を行っている様子を示す. 図の最上段には計測対象の反 射の様子を示す. 左が発泡塩化ビニール樹脂板, 右が夕 イルである。この結果では, ウサギの形のオブジェクト 表面に推定された反射特性を適用した場合の再現像を示 している．照明は，森の中の自然環境を採用した．図よ り，マテリアルごとの反射の様子が正確に再現されてい ることが分かる．また，光沢計の種類に依らず，同じょ うに再現結果が得られていることが分かる。なお，この ように計測された反射特性を，バーチャルリアリティや コンピュータグラフィックスの仮想空間構築のために利 用したり，プロダクトデザインとして最終イメージを具 現化するために利用することも可能である.

さらに 3 次元形状計測の結果と反射特性計測の結果を 合成したものを Fig. 5 に示す。この実験ではまず対象 物体の 3 次元形状と色を, カメラを用いて非接触に取得 する. 3 次元形状は高速に取得することが可能であ る ${ }^{13), 14)}$. 次に, 対象表面上の 1 点の反射特性を提案手 法で計測する，色のみを操作して，同特性を形状表面に 適用することで，実世界と同じ像を再現することができ る. 図で左は実際に撮影した写真, 右は計測結果によっ て再現したものである.このように，見分けが難しいレ ベルで質感を再現できる像を自由に生成できる。なお， この再現像は照明環境を変えて, あたかもこの対象物体 が異なる場所に存在するかのように再現することも可能 である。この実験では，写真を撮った環境の照明を適用 している．このようにデジタルアーカイブを高速化する ための目的でも利用可能であることが分かる.
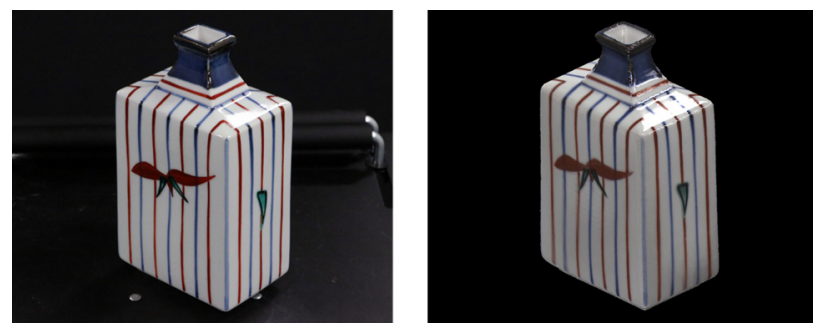

Fig. 5 Results of estimated BRDF with 3D shape.

\section{4. まとめ}

本稿では視覚的質感の高速計測について述べた．特に， 視覚的質感を構成する要素として重要な反射特性に着目 した，反射特性の定義とその計測事例を紹介し，計測の 高速化が困難であることを述べた，また，反射特性は人 間の知覚と大きく関わる点から，計測の戦略を多面的に 立てる必要があることを述べた，そのうえで，本稿では 機械学習を用いることで, 反射特性のモデル化とその推 定を同時最適化する手法を紹介した。この手法は, 高精 度化を達成できるだけでなく，システムをコンパクトに 設計する利点も有していることを述べた。最後に，実験 事例とともに様々な再現結果や利用方法を紹介した.

\section{参考文献}

1）小松英彦，質感の科学，朝倉書店 (2016).

2) 高松淳, 日浦慎作, 長原一, 富永昌治, 向川康博, コン ピュータビジョン 最先端ガイド 4 , アドコム・メディア (2011).

3 ) Dar'ya Guarnera, Giuseppe Claudio Guarnera, Abhijeet Ghosh, Ian Hall, Mashhuda Glencross, SIGGRAPH ASIA Courses (2016).

4) Wojciech Matusik, Hanspeter Pfister, Matt Brand, Leonard McMillan, ACM Transaction on Graphics 22 (2003) 3.

5 ) Jonathan Dupuy, Wenzel Jakob, ACM Transaction on Graphics 37 (2018) 6.

6 ) Fabio Pellacini, James A. Ferwerda, Donald P. Greenberg, Proc. of SIGGRAPH (2000).

7 ) Josh Wills, Sameer Agarwal, David Kriegman, Serge Belongie, ACM Transaction on Graphics 28 (2009) 4.

8 ) Masataka Sawayama, Yoshinori Dobashi, Makoto Okabe, Kenchi Hosokawa, Takuya Koumura, Toni Saarela, Maria Olkkonen, Shin'ya Nishida, bioRxiv (2019).

9) Wojciech Matusik, Hanspeter Pfister, Matthew Brand, Leonard McMillan, Proc. of Eurographics workshop on Rendering (2003).

10) Jannik Boll Nielsen, Henrik Wann Jensen, Ravi Ramamoorthi, ACM Transaction on Graphics 34 (2015) 6.

11) Szymon M. Rusinkiewicz, Proc. of Eurographics Workshop on Rendering Techniques (1998).

12）加地宏乃介, 渡辺義浩, 石川正俊, 第 21 回画像の認識 ・理解 シンポジウム (2018).

13) Satoshi Tabata, Michika Maruyama, Yoshihiro Watanabe, Masatoshi Ishikawa, Sensors, 19 (2019) 2.

14) Michika Maruyama, Satoshi Tabata, Yoshihiro Watanabe, Masatoshi Ishikawa, Proc. of IEEE meeting on applications of computer vision (2018). 